\title{
Analysis strategy based on wavelet decomposition for classification of voltage sags
}

\author{
J. Xargayó, J. Meléndez, J. Colomer, \\ Control Engineering and Intelligent Systems Group - Institute of Informatics and Applications \\ Universitat de Girona \\ Lluis Santaló s/n - 17004 Girona (Spain) \\ phone:+34 972418 486, fax:+34 972418 976, \\ e-mail: xargayo@eia.udg.es, quimmel@eia.udg.es, colomer@eia.udg.es
}

\begin{abstract}
In order to solve the problems by the perturbations in a voltage distribution system, is necessary the detection and identification of the different disturbing incidents: short-circuits, harmonic distortions, notchings, voltage dips (sags), etc. If it is possible, this detections can be effected automatically, without manual intervention, and as fastest as possible.
\end{abstract}

In this work we study the viability of the utilization of the wavelet transform for detection, identification and characterization of perturbations in a medium and high voltage distribution system [1]. In concrete, the work center the study in the voltage sags [2], and the possibility to divided the sags in different categories for facility futures studies about possible causes or effects[3].

The implementation of the algorithm was made with the 'Wavelets Toolbox', a toolbox of the MATLAB simulation program.

\section{Key words}

Wavelet transform, power quality, voltage sags, signal analysis.

\section{Introduction}

\section{A. Voltage sags}

In a voltage distribution system, all the perturbations are important in the term 'power quality', but the voltage sags has a relevant importance due to the number of success and the monetary impact they can produce. A voltage sag is defined as a sudden reduction (between 10$90 \%$ ) in the voltage magnitude (fig. 1), and lasting to 0.5 cycle to several seconds.

If we work in rms values, the voltage sag is represented in fig. 2, where is represented the three characteristics parameters: the voltage magnitude $(\Delta \mathrm{V})$, the time duration $(\Delta t)$ and the shape.

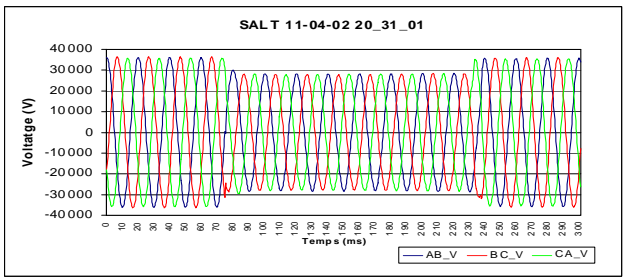

Fig.1: Example of voltage sag

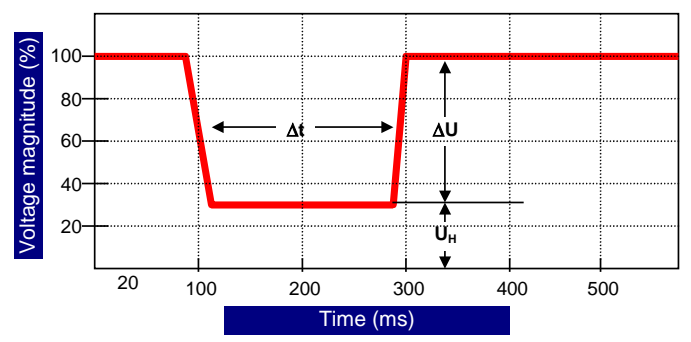

Fig. 2: Rms behaviour during a voltage sag

Usually, sags present rectangular shape characterized by a sudden decay in the instant that a perturbation is appeared, followed by a steady state in which the system is fault (the magnitude is limited because limit operation values are reached in some network devices) and finally when protective systems trips magnitude recovers original value. Nevertheless, sags can present some differences related with cause, network configuration and loads that allows a differentiation in classes, associated to shapes, with similar attributes. This different classes will be studied in chapter 2 .

\section{B. The discrete wavelet transform}

The discrete wavelet transform (DWT) is time-frequency decomposition of signals especially used to analyse 
transients. If $f(n)$ is the discrete function, the DWT is defined as:

$$
C[j, k]=\sum f[n] \Psi_{j, k}[n]
$$

where $\Psi_{\mathrm{j}, \mathrm{k}}[\mathrm{n}]$ is a discrete wavelet defined as:

$$
\Psi_{j, k}[n]=2^{-1 / 2} \Psi\left[2^{-j} n-k\right]
$$

with the parameters $a=2^{j}$ and $b=2^{j} k$.

The implementation of this transform is made by a filter scheme, based on a multi resolution analysis or pyramidal algorithm [4]. The signal (S) decomposition is obtained by filtering the signal with two complementary filters (a lowpass filter and a highpass filter). Output of these filters are named the approximation (A) and detail (D).

The approximation represents a high-scale, lowfrequency components of the signal whereas the detail contains a low-scale, high-frequency components of the signal.

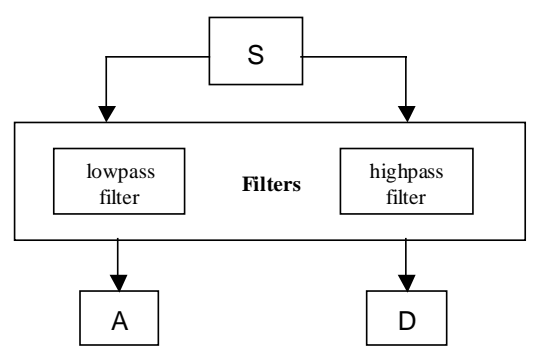

Figure 3: The multiresolution analysis

This decomposition process can be iterated, with successive approximations. Then, in a second level, the approximation signal $A_{1}$ is decomposed, with the same method (figure 3 ), with a new result: $A_{2}$ and $D_{2}$. The figure 4 shows a decomposition process, where the signal is broken down in lower resolution components. Equation (3) shows how the original signal can be reconstructed from Details and Approximations.

$\mathrm{S}=\mathrm{A}_{1}+\mathrm{D}_{1}=\mathrm{A}_{2}+\mathrm{D}_{2}+\mathrm{D}_{1}=\mathrm{A}_{3}+\mathrm{D}_{3}+\mathrm{D}_{2}+\mathrm{D}_{1}$

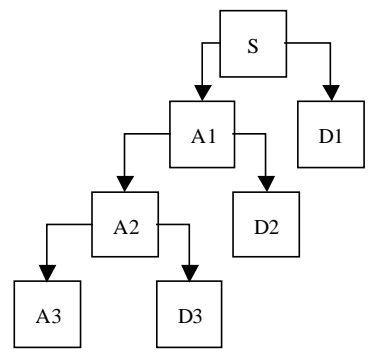

Figure 4: The wavelet decomposition tree (level 3)
This process can have an undefined number of levels, until to obtain a signal with a point. Iteration stops according to the type of signal and analysis criteria. The decomposition is limited to the number of samples $(\mathrm{N})$ because at each decomposition level $(\mathrm{J})$, the number of samples is reduced by two. The next expression denotes the limit decomposition level $(\mathrm{J})$ to be reached:

$$
2^{\mathrm{J}} \leq \mathrm{N}
$$

The filters cut-off frequency in each level $\mathrm{J}$ can be obtained by the expression:

$$
\text { cut_frq= (sample_frequency) / }\left(2^{\mathrm{J}+1}\right)
$$

In general terms, the wavelet decomposition of the signal $\mathrm{f}(\mathrm{n})$, where $\mathrm{n}$ is the number of samples, is:

$$
f(n)=A_{J}(n)+D_{1}(n)+D_{2}(n)+D_{3}(n)+\ldots . .+D_{J}(n)=A_{J}(n)+\sum_{K} D_{J}(n)
$$

where $A_{j}(n)$ (approximation signal) and $D_{j}(n)$ (detail signal) can be obtained from:

$$
\begin{aligned}
& A_{J}(n)=\sum_{K} A_{J, K} \bullet \Phi_{J, K}(n) \\
& D_{J}(n)=\sum_{K} D_{J, K} \bullet \Psi_{J, K}(n)
\end{aligned}
$$

and

$$
\begin{aligned}
& \Psi_{J, K} \text { is the mother wavelet (the highpass filter) } \\
& \Phi_{J, K} \text { is the scale function (the lowpass filter) } \\
& A_{J, K} \text { are the approximation coefficients } \\
& D_{J, K} \text { are the detail coefficients }
\end{aligned}
$$

with a final relationship:

$$
A_{J}(n)=A_{J-1}(n)+D_{J-1}(n)
$$

\section{Expert sags classification}

The classification process presented in this work has been executed over the data measured in a medium voltage network (located in Girona - Spain- and property of the utility FECSA-ENDESA).

In this work, we propose to classify sags depending on the qualitative shape of sags and to automatize this procedure as it was made for a 'human expert'. Then, we can manually classify the sags in four general groups: rectangle, trapezium, triangle and arc.

In Table I, we show the qualitative characteristics of each type of sags. 
TABLE I.- Sags Classification

\begin{tabular}{|l|l|l|l|l|}
\hline & $\begin{array}{l}\text { Drop } \\
\text { voltage }\end{array}$ & $\begin{array}{l}\text { Recovery } \\
\text { voltage }\end{array}$ & Duration & $\begin{array}{l}\text { Voltage } \\
\text { fall }\end{array}$ \\
\hline Rectangle & $\begin{array}{l}\text { Very } \\
\text { fast }\end{array}$ & $\begin{array}{l}\text { Very } \\
\text { fast }\end{array}$ & Large & High \\
\hline Trapezium & Fast & Fast & Short & Low \\
\hline Triangle & Fast & Slow & Short & Low \\
\hline Arc & Low & Low & ? & ? \\
\hline
\end{tabular}

Figure 5 shows an example (in rms) of these typologies of sags extracted from the data base used in the research. It is important to observe that the behaviour of the three phases can be different during the fall. It only depends of the type of fault occurred.

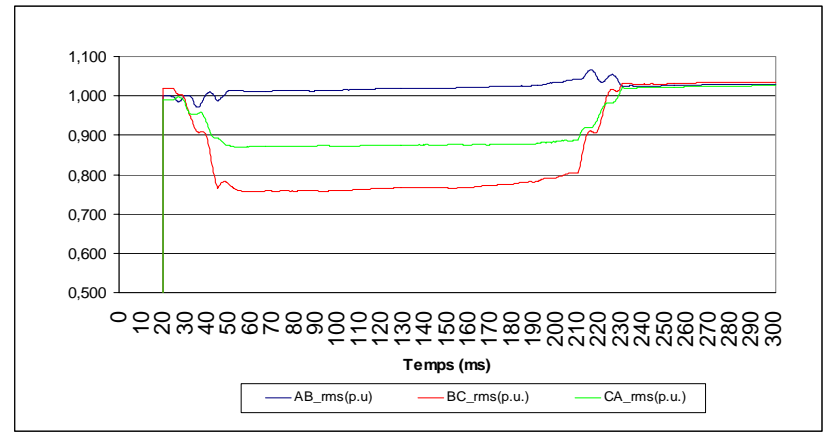

Figure 5.1. Rectangle

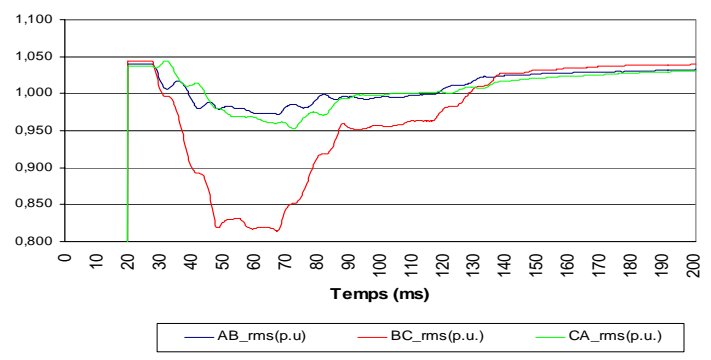

Figure 5.2. Trapezium

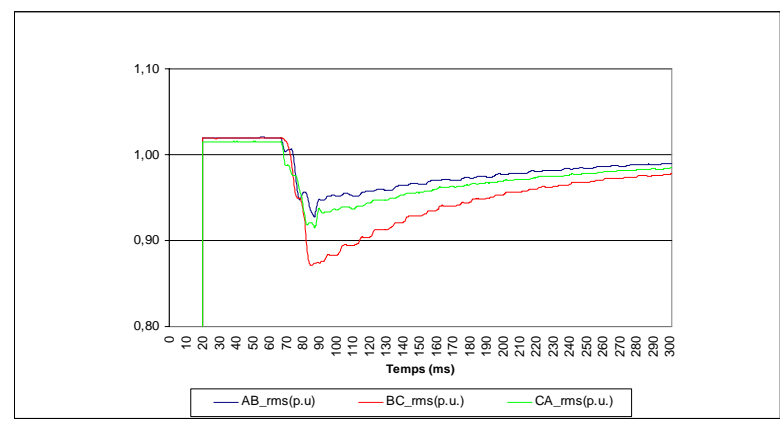

Figure 5.3. Triangle

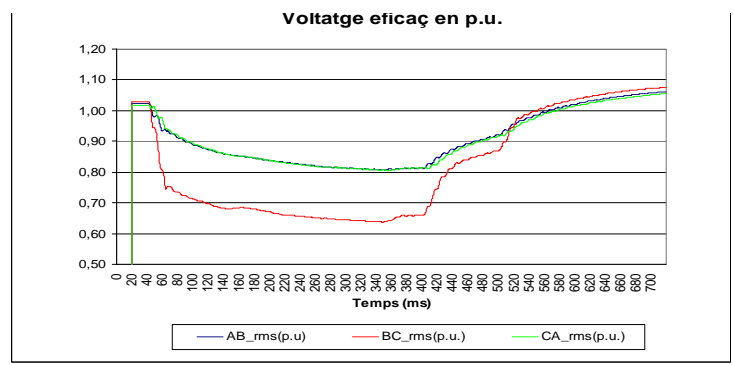

Figure 5.4. Arc

If we apply table I (with the help of an expert engineer) in the data base (with 122 perturbations, 104 of them voltage sags), the result of the qualitative classification, made for the 'human expert', is shown in figure 6.

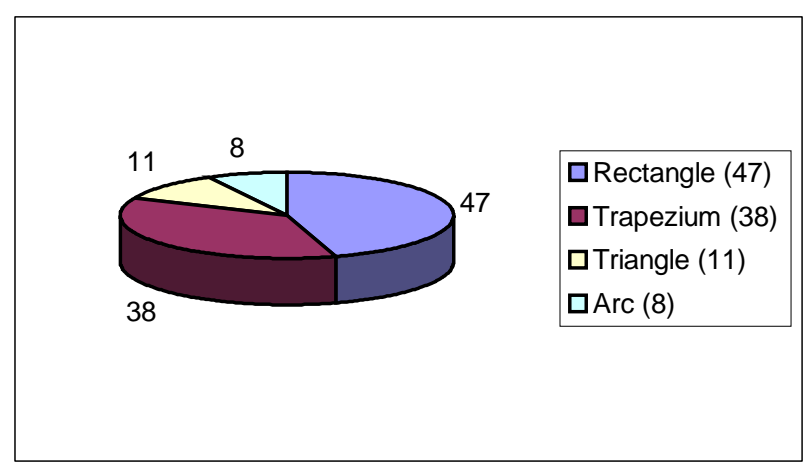

Figure 6: Distribution of voltage sags

\section{Automatic sags classification}

\section{A. The wavelet transform}

The process of the identification begin with a wavelet transform over the sag, using the wavelet toolbox from MATLAB.

In our case, the sample frequency of the signal is $3200 \mathrm{~Hz}$, then the maximum level of decomposition is 11 $\left(2^{11}=2048\right)$. This decomposition in 11 levels is showed in Table II, where we can found the margins of the frequencies of the approximations and details and the coefficients of each level.

TABLE II.- Wavelet Decomposition

\begin{tabular}{|l|c|c|c|}
\hline & $\mathrm{A}_{\mathrm{j}, \mathrm{k}}$ & $\begin{array}{c}\text { Number of } \\
\text { coefficients }\end{array}$ & $\mathrm{D}_{\mathrm{jk}}$ \\
\hline Level 1 & $0-800 \mathrm{~Hz}$ & 1152 & $800-1600 \mathrm{~Hz}$ \\
\hline Level 2 & $0-400 \mathrm{~Hz}$ & 576 & $400-800 \mathrm{~Hz}$ \\
\hline Level 3 & $0-200 \mathrm{~Hz}$ & 288 & $200-400 \mathrm{~Hz}$ \\
\hline Level 4 & $0-100 \mathrm{~Hz}$ & 144 & $100-200 \mathrm{~Hz}$ \\
\hline Level 5 & $0-50 \mathrm{~Hz}$ & 72 & $50-100 \mathrm{~Hz}$ \\
\hline Level 6 & $0-25 \mathrm{~Hz}$ & 36 & $25-50 \mathrm{~Hz}$ \\
\hline Level 7 & $0-12,5 \mathrm{~Hz}$ & 18 & $12,5-25 \mathrm{~Hz}$ \\
\hline Level 8 & $0-6,25 \mathrm{~Hz}$ & 10 & $6,25-12,5 \mathrm{~Hz}$ \\
\hline Level 9 & $0-3,12 \mathrm{~Hz}$ & 6 & $3,12-6,25 \mathrm{~Hz}$ \\
\hline Level 10 & $0-1,56 \mathrm{~Hz}$ & 4 & $1,56-3,12 \mathrm{~Hz}$ \\
\hline Level 11 & $0-1 \mathrm{~Hz}$ & 2 & $1-1,56 \mathrm{~Hz}$ \\
\hline
\end{tabular}


If we return to our data base (with $50 \mathrm{~Hz}$ main signal and high frequency components, due the perturbations), a decomposition until level 4 is enough for the proposed analysis. Then, the signal is discomposed by the expression:

$$
\mathrm{S}=\mathrm{A}_{4}+\mathrm{D}_{4}+\mathrm{D}_{3}+\mathrm{D}_{2}+\mathrm{D}_{1}
$$

The next steep is to select wavelet's family. This selection is very important for the final results, because depending of the wavelet selected the characteristics of the signal will be detected with best quality and speed.

In our study, the wavelet's family used is the Daubechies family, in concrete the Db4 [5]. If the coefficient of the Daubechies wavelet is low (4 in this case), the number of coefficients of the filter are fewer and the time localization of the wavelet is better, with best detection of the variations in high frequency.

The figure 7 show the graphical result of the wavelet transform without perturbation. Is important to remark that the process is made over the instantaneous values of the signal.

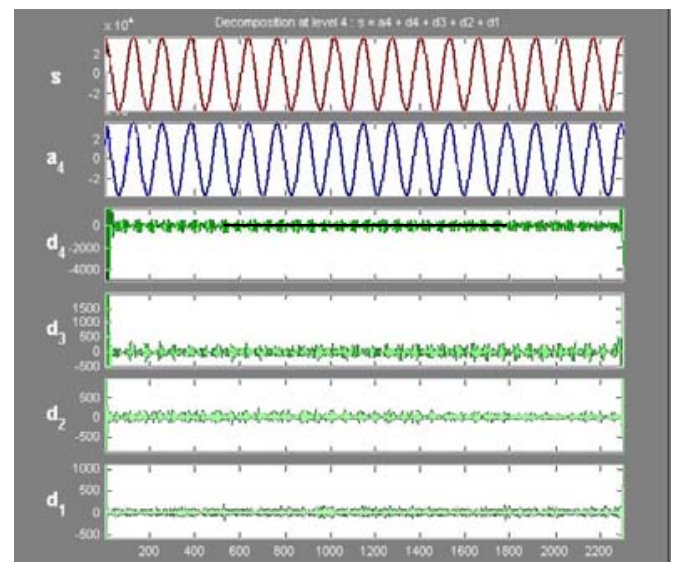

Figure 7. Wavelet transform.

From Table II and expression (1), we can see that $\mathrm{d} 1$ and $\mathrm{d} 2$ represent the high frequencies and $\mathrm{d} 3$ and $\mathrm{d} 4$ the low frequencies. The approximation a4 represent the value of the signal between 0 and $100 \mathrm{~Hz}$, where we can to found the main signal $(50 \mathrm{~Hz})$.

From the analysis, we can found the most of the values of the signal in approximation a4, but not in any detail (d1, d2, d3, d4), a normal situation in a signal without perturbation.

If the analysis is made in one of the rectangular sag contained in the data base, the results are different, and showed in figure 8 .

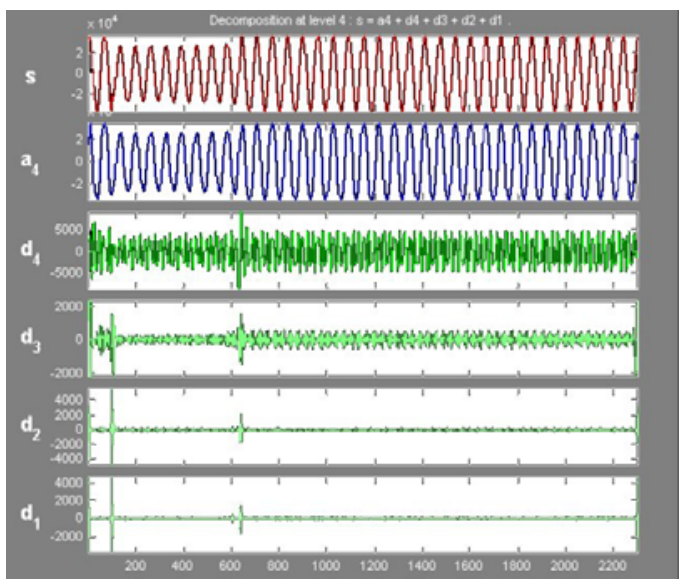

Figure 8: The Wavelet transform in a rectangular sag.

We can see that the transient characteristics are important, due basically for the fast drop and recovery voltage of the sag. This transient is detected in d1and d2 ( 2 peaks in each one). The value of the peak are high.

An other example of application is show in figure 9, in this case over a triangular sag. In this case, the best detection is made in d2: 1 peak with a important value, but, in general, fewer than in the rectangular case.

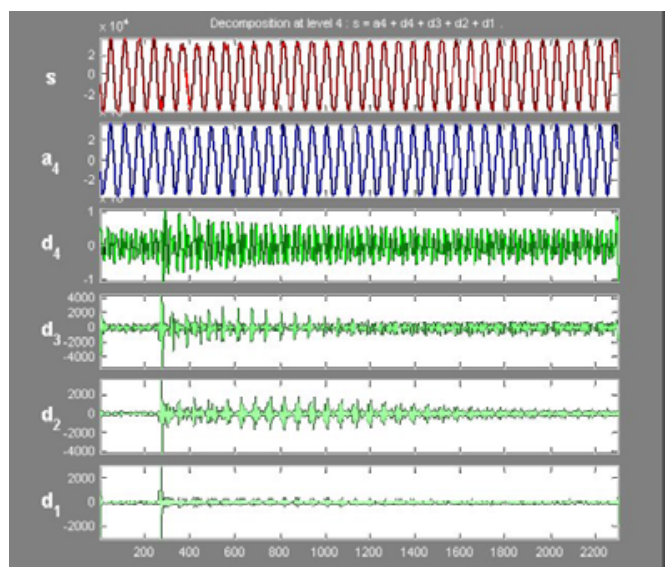

Figure 9: The Wavelet transform in a triangular sag.

Basically, and in each case, the extract information of the wavelet transform, and convenient processed, is saved in a file, which contain:

- Number of peaks in each discomposed signal (d1, d2, d3, d4)

- Maximum value of the peak in each discomposed signal

- $\quad$ Time of the oscillations

The Table III shows two examples of the data obtained for each type of sags. The cells C1, C2, C3 and C4 contain de number of peaks in each discomposed signal (d1, d2, d3 and d4) and the maximum value of the peaks. 
TABLE III - Example of the data obtained

\begin{tabular}{|l|c|c|c|c|c|}
\hline & C1 & C2 & C3 & C3 & $\begin{array}{c}\text { Time } \\
(\mathrm{ms})\end{array}$ \\
\hline Rectangle & 1 & 2 & 2 & 2 & 2014 \\
& 1000 & 2100 & 6100 & 3500 & \\
\hline Rectangle & 2 & 2 & 2 & 0 & 659 \\
& 2000 & 3200 & 3100 & -- & \\
\hline Trapezium & 0 & 2 & 2 & 2 & 832 \\
& -- & 210 & 780 & 1400 & \\
\hline Trapezium & 3 & 3 & 3 & 0 & 482 \\
& 3000 & 6000 & 3000 & -- & \\
\hline Triangle & 2 & 2 & 2 & 2 & 139 \\
& 7100 & 5700 & 14000 & 8200 & \\
\hline Triangle & 0 & 2 & 2 & 2 & 730 \\
& -- & 160 & 630 & 1250 & \\
\hline Arc & 1 & 3 & 3 & 3 & 980 \\
& 290 & 1200 & 1200 & 3900 & \\
\hline Arc & 0 & 3 & 3 & 3 & 690 \\
& -- & 230 & 1200 & 1400 & \\
\hline
\end{tabular}

This table is only an example of the application of the wavelet transform over the 104 sags. Is over the completed table where we made a qualitative and quantitative study, in order to found a general criteria to help in the final classification.

In based of this criteria, we made an algorithm to detect and classify the voltage sags.

\section{B. The classification algorithm}

The proposal algorithm for the classification is show in the next figure 8, divided for each type of sag. The algorithm is divided in each type of sag because is easier to understand and represented it, but is not the faster solution. If we want to obtain a fast algorithm, we must to improve the number of decisions, joint the different parts and making a new block of decision.

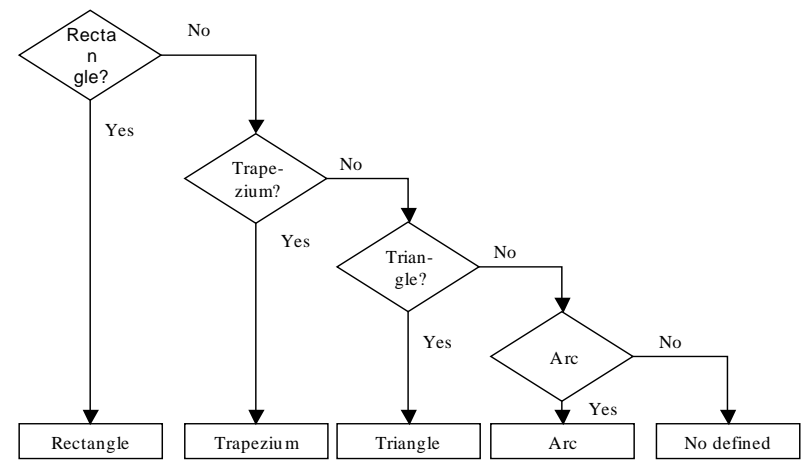

Figure 10: General classification algorithm

In the next figures we show every block of the general algorithm, and we can see that the parameters used in the comparators are the obtained from the wavelet transform: $\mathrm{ndx}=$ number of peaks in each detail of the signal (d1, d2, d3, d4)

$m d x=$ value of the maximum peak in each detail of the signal (d1, d2, d3, d4).

$\mathrm{t}=$ time (in $\mathrm{ms}$ )

In the algorithm contained in each block, we only show the affirmative path, in order to simplify the decision's tree. If the result of one of the decisions is negative, the algorithm continue in the next block, until to arrive, if it is necessary, to the 'ho defined' category.

All blocks begin the process with nd4, and continue, if it is necessary, with nd3, nd2 and, finally, nd1. We use, also, in same cases, md4, md3, md2, md1 and t.

\section{1) Rectangle sag}

In this case we use nd4, nd3, nd2, nd1 and md3. After the last comparison, we make another one, and divided the rectangular sag in two subgroup, short rectangle and long rectangle.

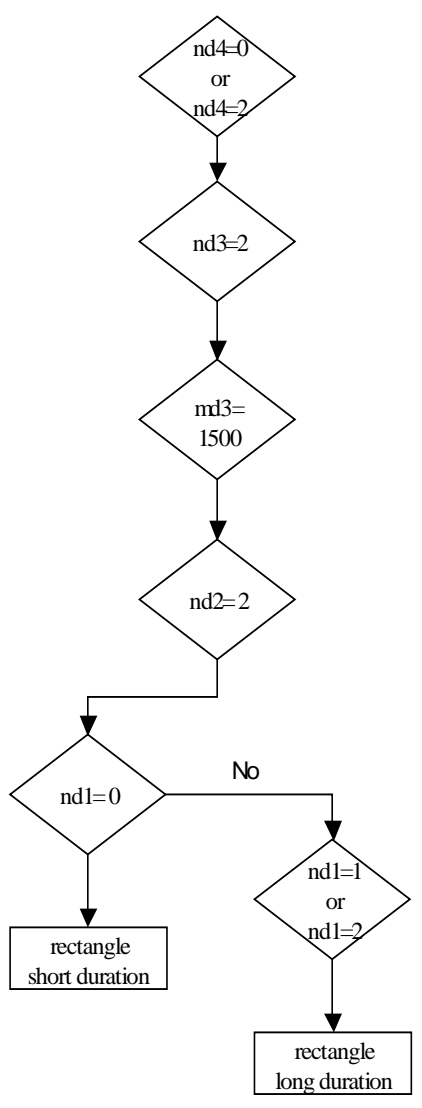

Figure 11: Rectangular sag

\section{2) Trapezium sag}

This case is similar to the anterior, and also divided the sag in two subgroups: trapezium-1 (a normal trapezium) and trapezium-2 (a trapezium with rectangular components) 


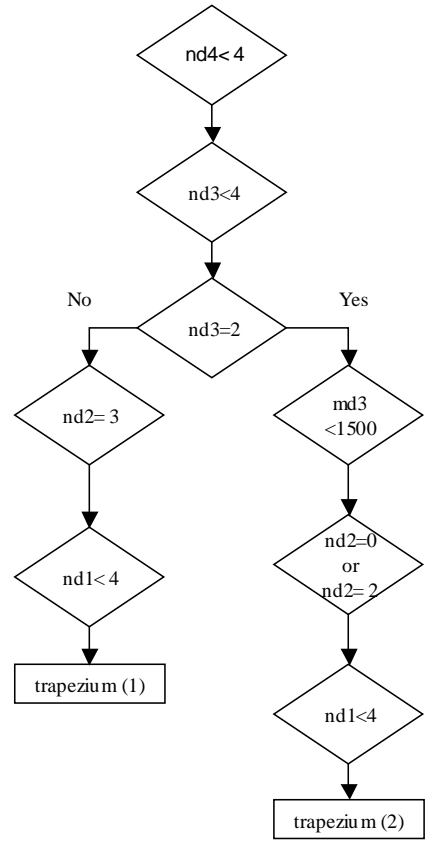

Figure 12: Trapezium sag

\section{3) Triangle sag}

This decision's tree is also similar to the others, using in this case the parameter $t$.

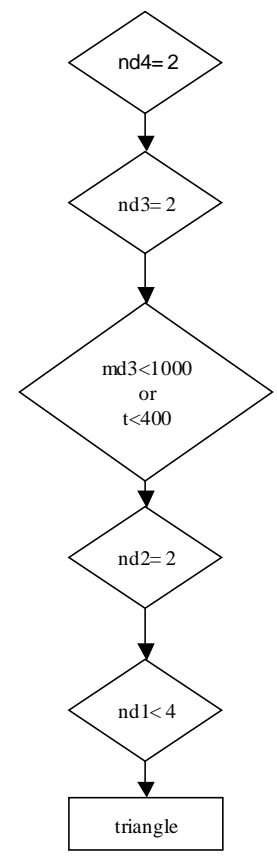

Figure 13: Triangle sag

\section{4) Arc sag}

Finally, we can see the last sag, similar, also, to the others.

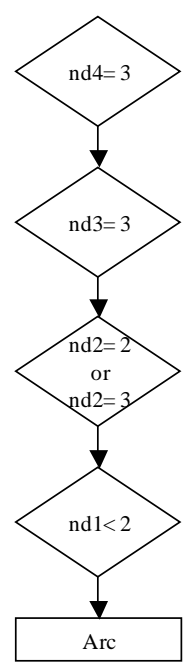

Figure 12: Arc sag

\section{Results of the classification}

The result of the classification of the all sags, following the rules of the algorithm proposed, are showed in the Table IV.

TABLE IV. Result of the classification

\begin{tabular}{|c|c|c|c|c|c|}
\hline & $(1)$ & $(2)$ & $(3)$ & $(4)$ & $(5)$ \\
\hline Rectangle & 47 & 44 & -- & 3 & $93,6 \%$ \\
\hline Trapezium & 38 & 33 & -- & 5 & $86,8 \%$ \\
\hline Triangle & 11 & 10 & -- & 1 & $90,9 \%$ \\
\hline Arc & 8 & 7 & -- & 1 & $87,5 \%$ \\
\hline TOTAL & 104 & 94 & -- & 10 & $90,1 \%$ \\
\hline
\end{tabular}

(1): Number of sags in each category, after the manual classification.

(2): Sags classified in each category, when this classification is agree with the manual.

(3): Sags classified in each category, but this classification is not agree with the manual.

(4): Sags of each category classified like 'no defined'.

(5): \% of correct classification

About this result, is important to remark the next points:

- When a sag is not classified in a category, then is considered as a 'no defined'. This occurs less than $10 \%$ of the cases.

- With this process of classification, a sag is classified in his correct category or in the 'no defined' category, but this method never exchange the category of the sags. 


\section{Conclusion}

This paper propose the utilization of the wavelet transform for detection and identification of the sags produced in a electrical distribution system.

The method proposed classify the sags in four groups:

- Rectangular

- Trapezium

- Triangle

- Arc

using an algorithm with the data obtained from the wavelet analysis. The results, showed in table IV, can be considered satisfactory.

The algorithm proposed can be modified, with more registration of sags. If the data base is bigger, is possible adjust the process of decision and to improve the results.

A new steep in this work is link the different sags with the causes. It is necessary, for this objective, complete the data base with more information about the sags.

\section{Acknowledgement}

This work has been partially supported by Spanish government and FEDER funds (SECSE, DPI2001-2198) and a contract between UdG and Endesa Distribution SAU.

\section{References}

[1] Lee, C-H. Wang, Y-J. Huang, W-L. “A literature survey of wavelets in power engineering applications". 2000. Vol 24, No 4, pp. 249-258

[2] Styvaktakis, E. Bollen, M.H.J. and Gu, Y.H. "Classification of power system events: voltage dips". Ninth International Conference on Harmonics and Quality of Power, Oct. 2000. Proceedings, Vol.2., pp. $745-750$

[3] Poisson, O. Rional, P. Meunier, M. "Detection and measurement of power quality disturbances using wavelets transform”. Transactions on Power Delivery, IEEE. July 2000. Vol. 15, No 3

[4] Mallat, S. “A theory for multiresolution signal decomposition: the wavelet representation," IEEE Pattern Anal. and Machine Intell. 1989. Vol. 11, no. 7, pp. 674693.

[5] Xiangxun, C. "Wavelet-based detection, localization, quantification and classification of short duration power quality disturbances”. Power Engineering Society Winter Meeting, IEEE. January 2002. Vol. 2 , pp. 931 -936

[6] Styvaktakis, E. Bollen, M.H.J. and Gu, Y.H. “Expert system for classification and analysis of power system events". Transactions on Power Delivery, IEEE. April 2002. Vol. 17, No 2, pp. 423-428

[7] Wilkinson, W.A. Cox, M.D. "Discrete wavelet analysis of power system transients". IEEE Transactions on Power Systems. Nov. 1996. Vol. 11, No 4.

[8] Pillay, A. Battacharjee. "Application of wavelets to model short-term power system disturbances". IEEE Transactions on Power Systems. Nov. 1996. Vol. 11, No 4. 